\title{
Determination of Heavy Metal-Toxic Element Content of Urban Qualified Wastewater and using it for Agricultural Purposes
}

\author{
Yasemin Damar Arifoglu \\ Sakarya University, Faculty of Engineering, \\ Environmental Engineering Department, Ankara, Turkey \\ E-mail:ydamar@sakarya.edu.tr \\ Hulya Karabas \\ Sakarya University, Faculty of Engineering, \\ Environmental Engineering Department, Ankara, Turkey \\ E-mail:hkarabas@sakarya.edu.tr
}

\begin{abstract}
In this study, treated wastewater obtained from the effluent of Hendek Wastewater Treatment Plant belonging to Sakarya Metropolitan Municipality was used. Pilot scale advanced treatment plants were established in laboratory environment and the usability of recovered waters for agricultural irrigation was investigated. Pilot plants are formed using sand filter, ultrafiltration and UV disinfection alternatives. The pilot facilities consist of three different alternatives; 1-sand filter + chlorination, 2-sand filter + UV disinfection and 3-sand filter + ultrafiltration + UV disinfection. Chemical oxygen demand (COD), suspended solids (SS), turbidity, conductivity, $\mathrm{pH}$ values were measured for each alternative facility. Fecal coliform, residual chlorine, sodium adsorption rate (SAR), specific ion toxicity, nutrient levels and heavy metal-toxic element analyzes were performed. Analysis results The Technical Procedure Communique of Wastewater Treatment Plants, Appendix 7. As a result of experimental studies, water obtained from alternative pilot plant number three was found to be more suitable for agricultural use compared to other pilot plants in terms of heavy metal and toxic elements.
\end{abstract}

Keywords: Urban wastewater, advanced treatment, heavy metals, toxic elements

DOI: $10.7176 / \mathrm{JSTR} / 5-4-06$

\section{Kentsel Nitelikli Arıtılmış Atıksuların Ağır Metal-Toksik Element İçeriğinin Belirlenmesi ve Tarımsal Amaçlı Kullanılabilirliğinin Araştırılması}

\begin{abstract}
Özet
Bu çalışmada, Sakarya Büyükșehir Belediyesi'ne ait Hendek Atıksu Arıtma Tesisi çıkışından temin edilen arıtılmış atık sular kullanılmıştır. Laboratuar ortamında pilot ölçekli ileri arıtma tesisleri kurularak geri kazanılan suların tarımsal sulama amacıyla kullanılabilirliği araştırılmıştır. Pilot tesisler kum filtresi, ultrafiltrasyon ve UV dezenfeksiyon alternatifleri kullanılarak oluşturulmuştur. Bu ünitelerin yer aldığ 3 farklı alternatiften oluşan pilot tesisler; 1-kum filtresi+klorlama, 2-kum filtre+UV dezenfeksiyon ve 3kum filtre+ultrafiltrasyon+UV dezenfeksiyon şeklinde sıralanmıştır. Her bir alternatif tesis için kimyasal oksijen ihtiyacı (KOİ), askıda katı madde (AKM), bulanıklık, iletkenlik, pH değerleri ölçülmüştür. Fekal koliform, bakiye klor, sodyum adsorbsiyon oranı (SAR), özgül iyon toksisitesi, nütrient seviyeleri ve ağır metal-toksik element analizleri yapılmıştır. Analiz sonuçları Atıksu Arıtma Tesisi Teknik Usuller Tebliği, AATTUT Ek 7' ye göre değerlendirilmiştir. Deneysel çalışmalar sonucunda 3 numaralı alternatif pilot tesisten elde edilen su ağır metal ve toksik element miktarları açısından diğer pilot tesislerle kıyaslandığında tarımsal amaçlı kullanıma daha uygun bulunmuştur.
\end{abstract}

Anahtar Kelimeler: Kentsel atıksu, ileri arıtma, ağır metal, toksik element 


\section{GíRiş}

$\mathrm{Su}$ yaşam olgusunu karşılayan ve canlıların hayatlarının idamesi için gerekli somut bir kavramdır. Dünyada su kullanımı; gıda-tarım (en fazla su kullanan sektörler), enerji, sanayi, yerleşim alanları (evsel ve içme suyu amaçlı kullanımlar), ekosistemlerin su ihtiyaçları olarak farklı temel başlıklar altında toplanabilir. Dünyadaki su kaynaklarının \%69'u tarımsal, \%19'u sanayi ve \%12'si evsel amaçlı kullanılmaktadır $[1,2]$. Tüm dünyada olduğu gibi ülkemizde de su kaynaklarının en fazla kullanıldığı alan tarımdır. Bu sebeple de tüm dünyada tarımsal sulama amaçlı olarak doğal su kaynaklarının ve şebeke suyunun kullanılması yerine arıtılmış atık suların kullanılabilmesi önemlidir [3, 4] .

Tüm Dünya'da mevcut atık sular incelendiğinde bu suların bünyelerinde ağır metal-toksik elementlerin, patojenlerin, organik ve inorganik besin maddelerinin, mikro ve makro kirleticilerin var olduğu bilinmektedir. Bu maddelerin atık sudaki bulunuş miktarları suların kaynağına ve kullanılan arıtma ünitelerinin verimlerine bağlı olarak değişmektedir [5]. Endüstriyel atıksular, kentsel atıksulara nazaran daha fazla miktarda ağır metal-toksik element içerirler. Atık suların bünyelerinde bulundurdukları ağır metal ve toksik element miktarlarının her ülke için tebliğlerle belirlenmiş yasal sınır değerlere uygun olması gerekir. Ülkemizde de kentsel atıksu arıtma tesislerinden çkan arııılmış atık suların kullanılabilirliği Dünya Sağlık Örgütü (WHO) standartları gözönünde bulundurularak hazırlanmış olan Atıksu Arıtma Tesisi Teknik Usuller Tebliği (AATTUT) Ek.7'ye göre değerlendirilmektedir [6].

Tüm Dünya'da ağır metal ve kirleticilerin gideriminde geleneksel arıtma tesisleri yetersiz kaldığ için verimleri daha yüksek olan ileri arıtma ünitelerinden oluşan tesisler kullanılmaktadır. İleri arıtma ünitelerinden çıkan sulardaki ağır metal-toksik element konsantrasyonları farklılık gösterir. İnsan ve hayvan sağlı̆̆ açısından son derece olumsuz etkileri olan ağır metallerin toprak ve suda bulunabilecek düşük konsantrasyonları dahi istenmemektedir. Bitkiler ve özellikle de depo kök yapısına sahip olan yumrulu bitkiler, kolaylıkla bünyelerine toprakta ve suda varolan ağır metal-toksik elementleri alırlar. Bünyesinde ağır metal bulunan bitkilerle beslenen insan ve hayvanlarda besin zinciri yoluyla bu ağır metalleri kendi vücutlarına alarak depolarlar. Sağlık açısından büyük bir risk oluşturan ağır metaller canlı organizmada birikerek kanserojen etki yaratırlar. Bu yüzünden sulama suyunda ağır metallerin varlığının tespiti ve kontrolü oldukça önemlidir $[7,8,9,10,11]$.

Bu çalışmada, Sakarya İl'i Hendek İlçe'sinde bulunan Kentsel Atıksu Arıtma Tesisi ikincil arıtmadan çıkan arıtılmış atık sular üç farklı alternatifle oluşturulan ileri arıtma ünitelerine sahip pilot ölçekli tesislerde ileri arıtmaya tabi tutularak buradan elde edilen arıtılmış suların ağır metal-toksik element içerikleri ölçülmüştür. Her bir tesisten elde edilen ölçüm sonuçları neticesinde bu suların tarımsal sulama amaçlı olarak kullanılıp kullanılamayacağı araştırılmıştır.

\section{MATERYAL VE YÖNTEM}

\subsection{Materyal}

$\mathrm{Bu}$ çalş̧mada laboratuar ölçekli tesiste, KF-835-5600 model kum filtre kullanıldı. Ultraviyole dezenfeksiyon işleminde UV254nm dalga boylu dezenfeksiyon cihazı kullanıldı. Bulanıklık ölçümleri Merck marka 1100T model cihaz ile yapıldı. pH ve elektriksel iletkenlik ölçümleri için WTW marka 3410model ölçüm cihazı kullanıldı. Askıda Katı Madde(AKM) gravimetrik yöntem kullanılarak (SM 2510 B), KOİ Merck marka Pharo 300 model spektrofotometre ile ölçülmüştür. Al, As, B, Cr, Co, Cu, $\mathrm{F}, \mathrm{Fe}, \mathrm{mü} \mathrm{Pb}, \mathrm{Mn}, \mathrm{Mo}, \mathrm{Ni}, \mathrm{Zn}, \mathrm{Na}, \mathrm{Mg}, \mathrm{Ca}, \mathrm{Cl}^{-}$metallerinin ölçümleri Aksaray Üniversitesi Bilimsel ve Teknolojik Uygulama ve Araştırma Merkezi (ASÜBTAM) tarafından gerçekleştirilmiştir.

\subsection{Yöntem}

Çalışmada ilk olarak Hendek Kentsel Atıksu Arıtma Tesisi (Şekil 1) çıkışından alınan arıtılımış sular pilot ölçekli tesislerde kullanılmak üzere depolanmışıır. Laboratuar ölçekli deney düzenekleri üç farklı alternatifli olarak planlanmıştır. Bu pilot ölçekli tesisler aşağıda belirtilen ünitelerden oluşmaktadır.

I. alternatif pilot ölçekli tesis $\rightarrow$ kum filtre + klorlama,

II. alternatif pilot ölçekli tesis $\rightarrow$ kum filtre + UV dezenfeksiyon,

III. alternatif pilot ölçekli tesis $\rightarrow$ kum filtre + ultrafiltrasyon + UV dezenfeksiyon 


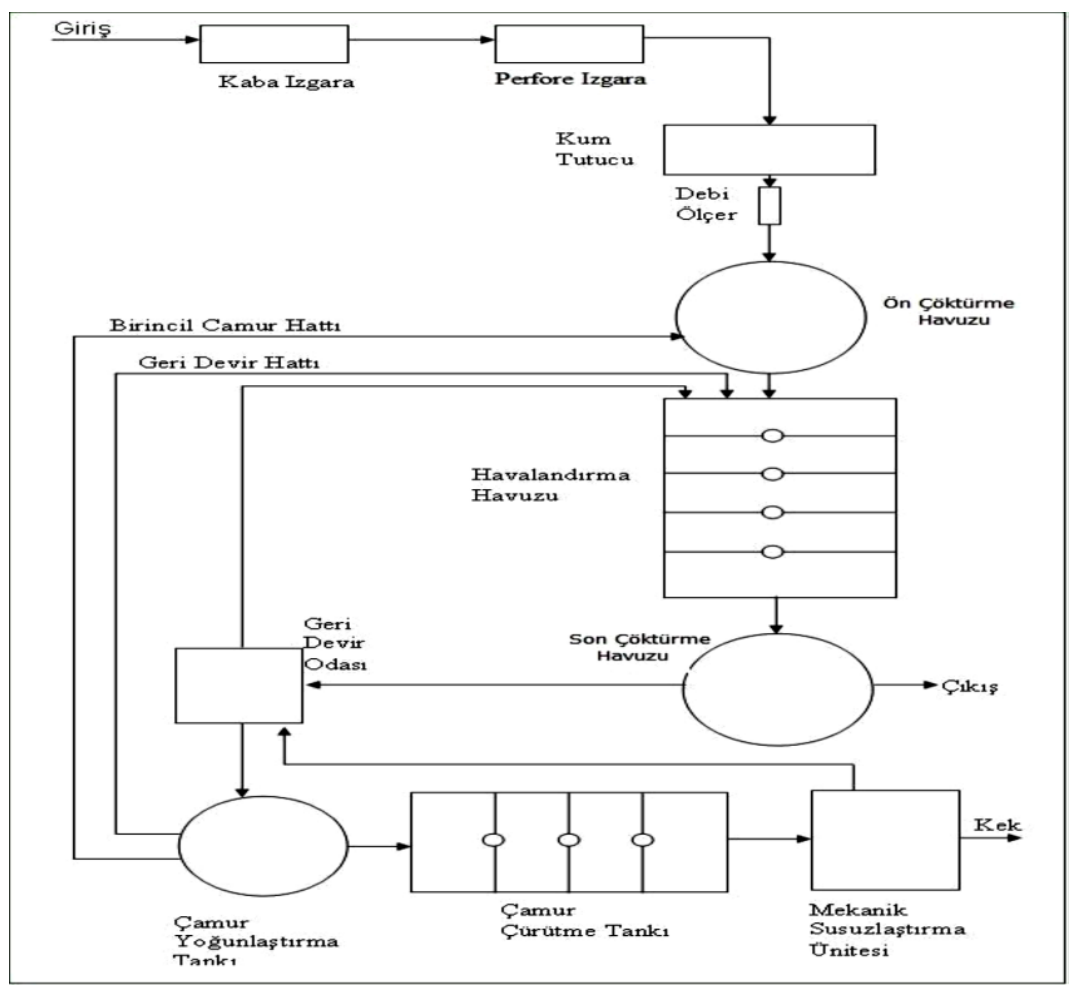

Şekil 1. Tesise ait akım şeması

Şekil 2'de I. alternatif pilot tesise ait kum filtre ve klor ile klorlama yapılan ünitelerden oluşan akım şeması yer almaktadır.

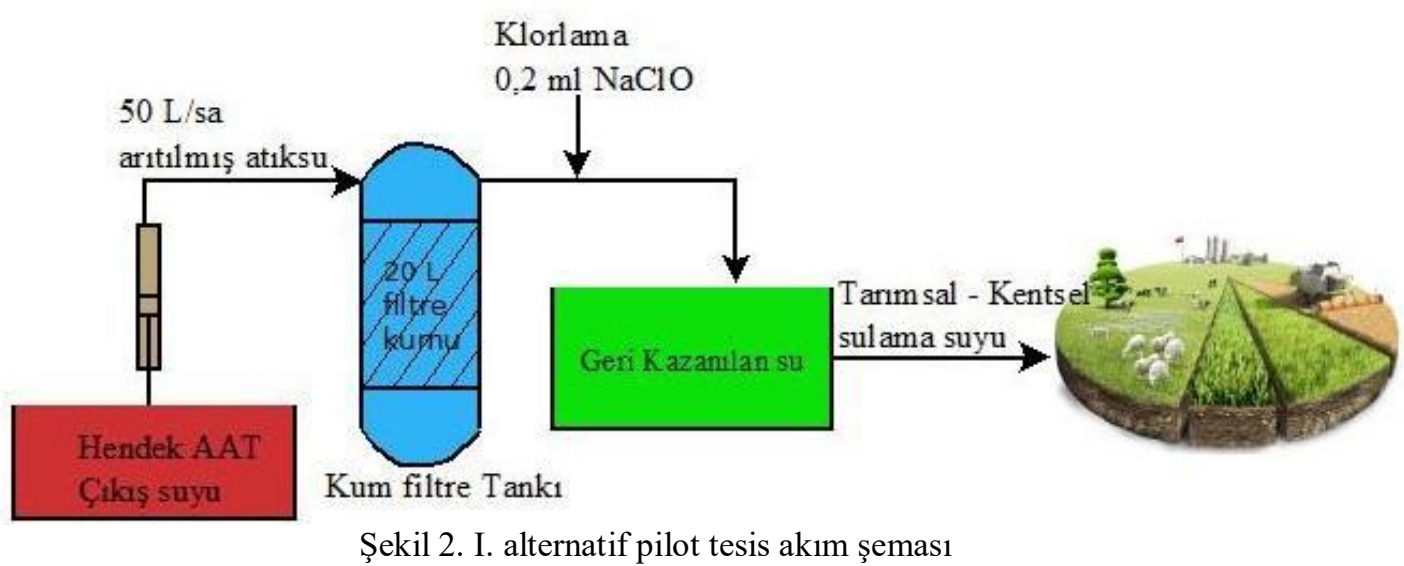

Şekil 3'de II. alternatif pilot tesise ait kum filtre ve UV dezenfeksiyon ünitelerinden oluşan akım şeması görülmektedir.

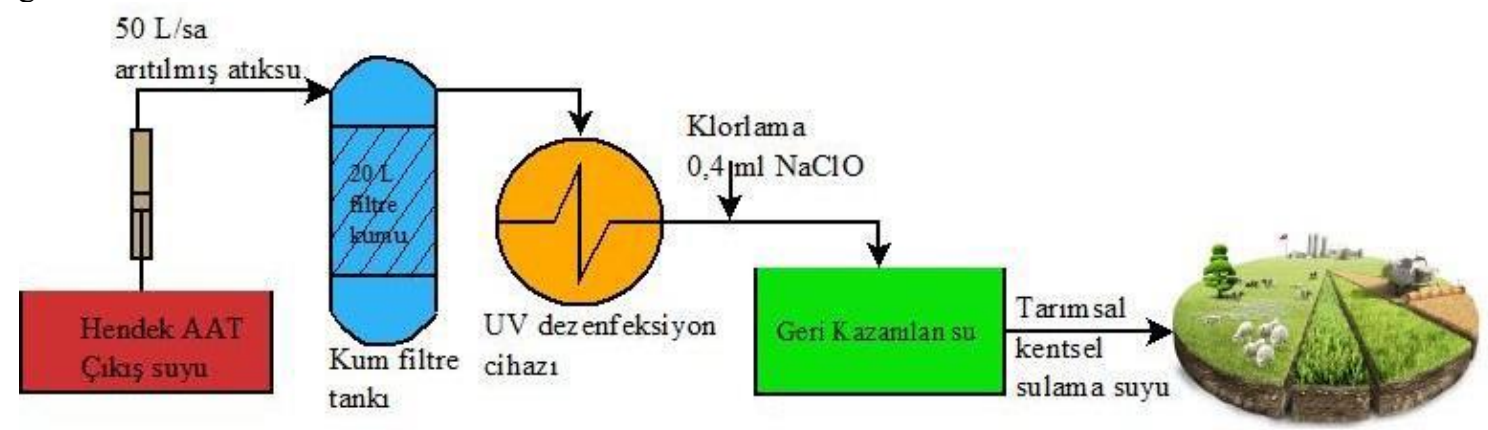

Şekil 3. II. alternatif pilot tesis akım şeması 
Şekil 4'de III. alternatif pilot tesise ait kum filtre, ultrafiltrasyon ve UV dezenfeksiyon ünitelerinden oluşan akım şeması görülmektedir.

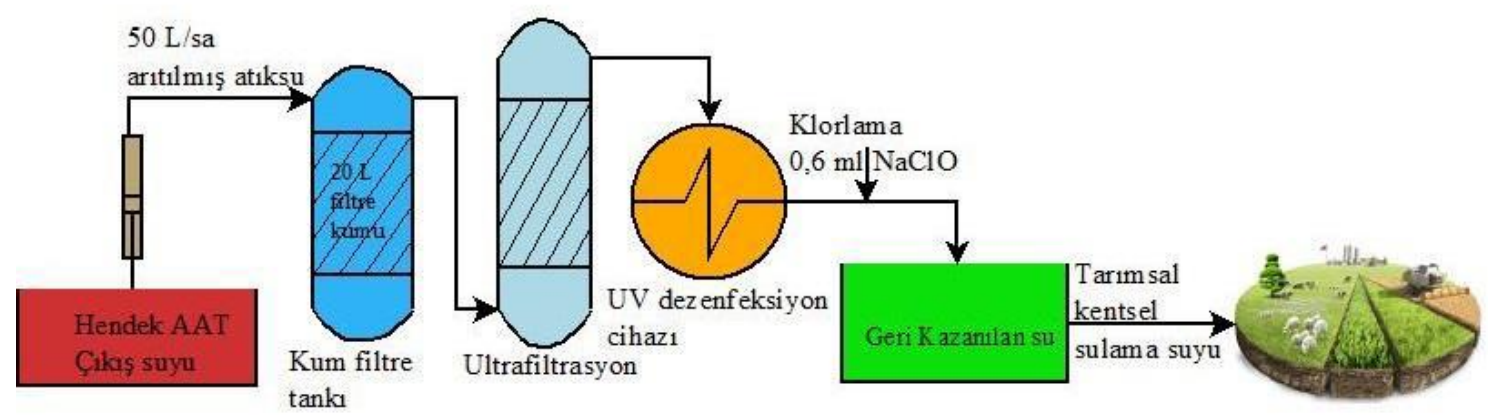

Şekil 4. III. alternatif pilot tesis akım şeması

Laboratuar koşullarında üç farklı alternatifli olarak oluşturulan pilot ölçekli tesislerde arıtma tesisinden alınıp depolanan arıtılmış atık suların ağır metal-toksik element değerleri ölçülmüştür. Her bir tesisten elde edilen ölçüm sonuçları neticesinde bu suların tarımsal sulama amaçlı olarak kullanılıp kullanılamayacağı araştırılmıştır. Bor pilot tesislerin tümünde AATTUT Tablo Ek 7.6' da hassasiyet dereceleri açısından incelendiğinde, hassas $(0,5-1 \mathrm{mg} / \mathrm{L})$ derecesine girmektedir.

\subsection{Atıksuyun Kaynağı ve Karakterizasyonu}

$\mathrm{Bu}$ çalışmada Sakarya İl'i Hendek İlçesi'nde bulunan atıksu arıtma tesisine ait sular ikincil arıtmadan çıktıktan sonra üç alternatifli olarak oluşturulan ileri arıtma pilot tesislerinde arıtmaya tabi tutulmuştur. İlçede küçük ölçekli sanayi kuruluşları faaliyet göstermektedir. Ağırlıklı olarak otomotiv, madeni eşya sanayi, plastik, tekstil, orman ürünleri, kimya, elektrik malzeme imalatı, yapı malzemeleri, gıda sektörlerine ait tesisler bulunmaktadır. Hendek atıksu arıtma tesisinde $12.000 \mathrm{~m}^{3} /$ gün atısu arıtılmaktadır. Arıtılmış atık sular Dilsiz Deresine deşarj edilmektedir. Hendek atık su çıkış değerleri, 2016-2017 yılları arasında 1 yıl süre ile ölçülmüştür.

Tablo 1. Hendek Atıksu Arıtma Tesisi ortalama giriş ve çıkış değerleri

\begin{tabular}{|c|c|c|}
\hline Parameters & $\begin{array}{c}\text { Hendek Atıksu } \\
\text { Arıtma Tesisi } \\
\text { Ortalama Giriş } \\
\text { Değerleri } \\
\end{array}$ & $\begin{array}{c}\text { Hendek Atıksu Arıtma Tesisi } \\
\text { Ortalama Çıkış Değerleri } \\
\text { (Pilot Tesisler İçin Ortalama } \\
\text { Giriş Değerleri ) }\end{array}$ \\
\hline KOİ (mg/L) & 193 & 46 \\
\hline $\mathrm{BOI}_{5}(\mathrm{mg} / \mathrm{L})$ & 130 & 25 \\
\hline Askıda Katı Madde (AKM) (mg/L) & 91 & 20 \\
\hline İletkenlik $(\mu \mathrm{s} / \mathrm{cm})$ & 1200 & 840 \\
\hline $\mathrm{pH}$ & 7.4 & 7.66 \\
\hline $\begin{array}{l}\text { Fekal Koliform } \\
\text { (say1/100 mL) }\end{array}$ & - & 150 \\
\hline $\begin{array}{l}\text { Toplam Koliform } \\
\text { (sayı/100mL) }\end{array}$ & - & 1500 \\
\hline Bulanıklık (NTU) & - & 5.12 \\
\hline
\end{tabular}

\section{BULGULAR VE TARTIŞMA}

\subsection{Birinci Alternatif Pilot Tesise Ait Sulama Suyunun Ăğr Metal İçerikleri}

Tablo 2'de I. alternatife ait pilot tesisin çıkış suyunda ölçülen ağır metal-toksik element değerleri AATTUT'nde yer alan sınır değerler ile karşılaştırılmıştır. Pilot tesisten çıkan ileri arıtmada arıtılmış atık sulara ait ağır metal-toksik element değerleri AATTUT'da izin verilen maksimum sınır değerlerin oldukça altında kalarak tarımsal sulamada güvenle kullanılabileceği görülmüş̧ür. 
Tablo 2. I. alternatif pilot tesisin çıkış suyunda ölçülen ağır metal-toksik element değerleri

\begin{tabular}{|c|c|c|c|c|}
\hline \multirow[b]{2}{*}{ ELEMENTLER } & \multirow[b]{2}{*}{$\begin{array}{c}\text { Birim alana } \\
\text { verilebilecek } \\
\text { maksimum } \\
\text { toplam } \\
\text { miktarlar, } \\
\text { kg/ha }\end{array}$} & \multicolumn{2}{|c|}{$\begin{array}{l}\text { İzin verilen maksimum } \\
\text { konsantrasyonlar }\end{array}$} & \multirow[b]{2}{*}{$\begin{array}{l}\text { I. Alternatif } \\
\text { (Kum filtre + } \\
\text { Klorlama) } \\
(\mathrm{mg} / \mathrm{L})\end{array}$} \\
\hline & & $\begin{array}{c}\text { Her türlü } \\
\text { zeminde } \\
\text { sürekli } \\
\text { sulama } \\
\text { yapılması } \\
\text { durumunda } \\
\text { sinır değerler } \\
(\mathrm{mg} / \mathrm{L})\end{array}$ & $\begin{array}{c}\mathrm{pH} \text { değeri } \\
6.0-8.5 \\
\text { arasında olan } \\
\text { killi } \\
\text { zeminlerde } 24 \\
\text { yıldan daha az } \\
\text { sulama } \\
\text { yapıldığında, } \\
\text { (mg/L) }\end{array}$ & \\
\hline Alüminyum(Al) & 4600 & 5,0 & 20,0 & 0,004 \\
\hline Arsenik(As) & 90 & 0,1 & 2,0 & 0,01 \\
\hline Berilyum(Be) & 90 & 0,1 & 0,5 & 0 \\
\hline Bor(B) & 680 & - & 2,0 & 0,001 \\
\hline Kadminyum(Cd) & 9 & 0,01 & 0,05 & 0 \\
\hline $\operatorname{Krom}(\mathrm{Cr})$ & 90 & 0,1 & 1,0 & 0,18 \\
\hline Kobalt(Co) & 45 & 0,05 & 5,0 & 0,005 \\
\hline $\operatorname{Bakır}(\mathrm{Cu})$ & 190 & 0,2 & 5,0 & 0 \\
\hline Florür(F) & 920 & 1,0 & 15,0 & 0,25 \\
\hline $\operatorname{Demir}(\mathrm{Fe})$ & 4600 & 5,0 & 20,0 & 0,0005 \\
\hline $\operatorname{Kurşun}(\mathrm{Pb})$ & 4600 & 5,0 & 10,0 & 0 \\
\hline Lityum(Li) & - & 2,5 & 2,5 & 0,04 \\
\hline Manganez(Mn) & 920 & 0,2 & 10,0 & 0,1 \\
\hline Molibden(Mo) & 9 & 0,01 & $0,05^{2}$ & 0,0002 \\
\hline Nikel(Ni) & 920 & 0,2 & 2,0 & 0 \\
\hline Selenyum(Se) & 16 & 0,02 & 0,02 & 0,002 \\
\hline Vanadyum(V) & - & 0,1 & 1,0 & 0,019 \\
\hline Çinko(Zn) & 1840 & 2,0 & 10,0 & 0,1 \\
\hline
\end{tabular}

\section{2. İkinci Alternatif Sulama Suyu Eser Elementlerinin Değerlendirilmesi}

Tablo 3'de II. alternatife ait pilot tesisin çıkış suyunda ölçülen ağır metal-toksik element değerleri tebliğ değerleri ile karşılaştırılmıştır. Pilot tesisten çıkan suların ağır metal-toksik element değerleri tebliğde izin verilen maksimum sınır değerlerden düşük olduğu için bu pilot tesisten çıkan sularda tarımsal sulama amaçlı kullanıma uygundur. 
Tablo 3. II. alternatif pilot tesisin çıkıs suyunda ölçülen ağır metal-toksik element değerleri

\begin{tabular}{|c|c|c|c|c|}
\hline \multirow[b]{2}{*}{ Elementler } & \multirow[b]{2}{*}{$\begin{array}{l}\text { Birim alana } \\
\text { verilebilecek } \\
\text { maksimum } \\
\text { toplam } \\
\text { miktarlar, } \\
\text { kg/ha }\end{array}$} & \multicolumn{2}{|c|}{$\begin{array}{l}\text { İzin verilen maksimum } \\
\text { konsantrasyonlar }\end{array}$} & \multirow[b]{2}{*}{$\begin{array}{l}\text { II. Alternatif } \\
\text { Kum filtre + } \\
\text { UV } \\
\text { Dezenfeksiyon } \\
\quad(\mathrm{mg} / \mathrm{L})\end{array}$} \\
\hline & & $\begin{array}{l}\text { Her türlü } \\
\text { zeminde } \\
\text { sürekli } \\
\text { sulama } \\
\text { yapılması } \\
\text { durumun } \\
\text { da sınır } \\
\text { değerler } \\
\text { (mg/L) }\end{array}$ & $\begin{array}{c}\text { pH değeri } \\
6.0-8.5 \\
\text { arasında olan } \\
\text { killi } \\
\text { zeminlerde } \\
\text { 24yıldan daha } \\
\text { az sulama } \\
\text { yapıldığında, } \\
\text { (mg/L) }\end{array}$ & \\
\hline Alüminyum(Al) & 4600 & 5,0 & 20,0 & 0,008 \\
\hline Arsenik(As) & 90 & 0,1 & 2,0 & 0,013 \\
\hline Berilyum(Be) & 90 & 0,1 & 0,5 & 0,0003 \\
\hline Bor(B) & 680 & - & 2,0 & 0,001 \\
\hline $\operatorname{Kadminyum}(\mathrm{Cd})$ & 9 & 0,01 & 0,05 & 0 \\
\hline $\operatorname{Krom}(\mathrm{Cr})$ & 90 & 0,1 & 1,0 & 0,019 \\
\hline Kobalt(Co) & 45 & 0,05 & 5,0 & 0,004 \\
\hline Bakır(Cu) & 190 & 0,2 & 5,0 & 0,031 \\
\hline Florür(F) & 920 & 1,0 & 15,0 & 0,09 \\
\hline Demir(Fe) & 4600 & 5,0 & 20,0 & 0,1 \\
\hline Kurşun(Pb) & 4600 & 5,0 & 10,0 & 0 \\
\hline Lityum(Li) & - & 2,5 & 2,5 & 0,03 \\
\hline Manganez(Mn) & 920 & 0,2 & 10,0 & 0,03 \\
\hline Molibden(Mo) & 9 & 0,01 & $0,05^{2}$ & 0,0002 \\
\hline Nikel(Ni) & 920 & 0,2 & 2,0 & 0,07 \\
\hline Selenyum(Se) & 16 & 0,02 & 0,02 & 0,001 \\
\hline Vanadyum(V) & - & 0,1 & 1,0 & 0,017 \\
\hline Çinko(Zn) & 1840 & 2,0 & 10,0 & 0,15 \\
\hline
\end{tabular}

\section{3. Üçüncü Alternatif Sulama Suyu Eser Elementlerinin Değerlendirilmesi}

Tablo 4'de III. alternatif pilot tesise ait ağır metal-toksik element değerleri, AATTUT Ek 7. tebliğ değerleri ile karşılaştırıldığında çıkış suyu değerleri yönetmeliğin altındadır ve sulama suyu olarak kullanıma uygundur. 
Tablo 4. III. alternatif pilot tesisin çıkış suyunda ölçülen ağır metal-toksik element değerleri

\begin{tabular}{|c|c|c|c|c|}
\hline \multirow[b]{2}{*}{ ELEMENTLER } & \multirow{2}{*}{$\begin{array}{c}\text { Birim alana } \\
\text { verilebilecek } \\
\text { max toplam } \\
\text { miktarlar, } \\
\text { kg/ha }\end{array}$} & \multicolumn{2}{|c|}{$\begin{array}{l}\text { İzin verilen max } \\
\text { konsantrasyonlar }\end{array}$} & \multirow{2}{*}{$\begin{array}{l}\text { III. Alternatif } \\
\text { KF }+ \text { UF + UV } \\
\text { Dezenfeksiyon } \\
\quad(\mathrm{mg} / \mathrm{L})\end{array}$} \\
\hline & & $\begin{array}{l}\text { Her türlü } \\
\text { zeminde } \\
\text { sürekli } \\
\text { sulama } \\
\text { yapılması } \\
\text { durumund } \\
\text { a sinır } \\
\text { değerler } \\
(\mathrm{mg} / \mathrm{L})\end{array}$ & $\begin{array}{l}\text { pH değeri 6.0- } \\
8.5 \text { arasında } \\
\text { olan killi } \\
\text { zeminlerde } \\
\text { 24yıldan daha } \\
\text { az sulama } \\
\text { yapıldığında, } \\
\text { (mg/L) }\end{array}$ & \\
\hline Alüminyum(Al) & 4600 & 5,0 & 20,0 & 0,264 \\
\hline Arsenik(As) & 90 & 0,1 & 2,0 & 0,04 \\
\hline Berilyum(Be) & 90 & 0,1 & 0,5 & 0 \\
\hline Bor(B) & 680 & - & 2,0 & 0,4 \\
\hline Kadminyum(Cd) & 9 & 0,01 & 0,05 & 0 \\
\hline $\operatorname{Krom}(\mathrm{Cr})$ & 90 & 0,1 & 1,0 & 0,007 \\
\hline Kobalt(Co) & 45 & 0,05 & 5,0 & 0,003 \\
\hline $\operatorname{Bakur}(\mathrm{Cu})$ & 190 & 0,2 & 5,0 & 0,012 \\
\hline Florür(F) & 920 & 1,0 & 15,0 & 0,1 \\
\hline Demir(Fe) & 4600 & 5,0 & 20,0 & 0 \\
\hline $\operatorname{Kurşun}(\mathrm{Pb})$ & 4600 & 5,0 & 10,0 & 0,018 \\
\hline Lityum(Li) & - & 2,5 & 2,5 & 0,013 \\
\hline Manganez(Mn) & 920 & 0,2 & 10,0 & 0,003 \\
\hline Molibden(Mo) & 9 & 0,01 & $0,05^{2}$ & 0,0003 \\
\hline Nikel(Ni) & 920 & 0,2 & 2,0 & 0,033 \\
\hline Selenyum(Se) & 16 & 0,02 & 0,02 & 0,014 \\
\hline Vanadyum(V) & - & 0,1 & 1,0 & 0,014 \\
\hline Çinko(Zn) & 1840 & 2,0 & 10,0 & 0,018 \\
\hline
\end{tabular}

Şekil 5'te üç farklı alternatiften oluşan pilot tesislerin ağır metal konsantrasyonları karşılaştırmalı olarak verilmiştir. 


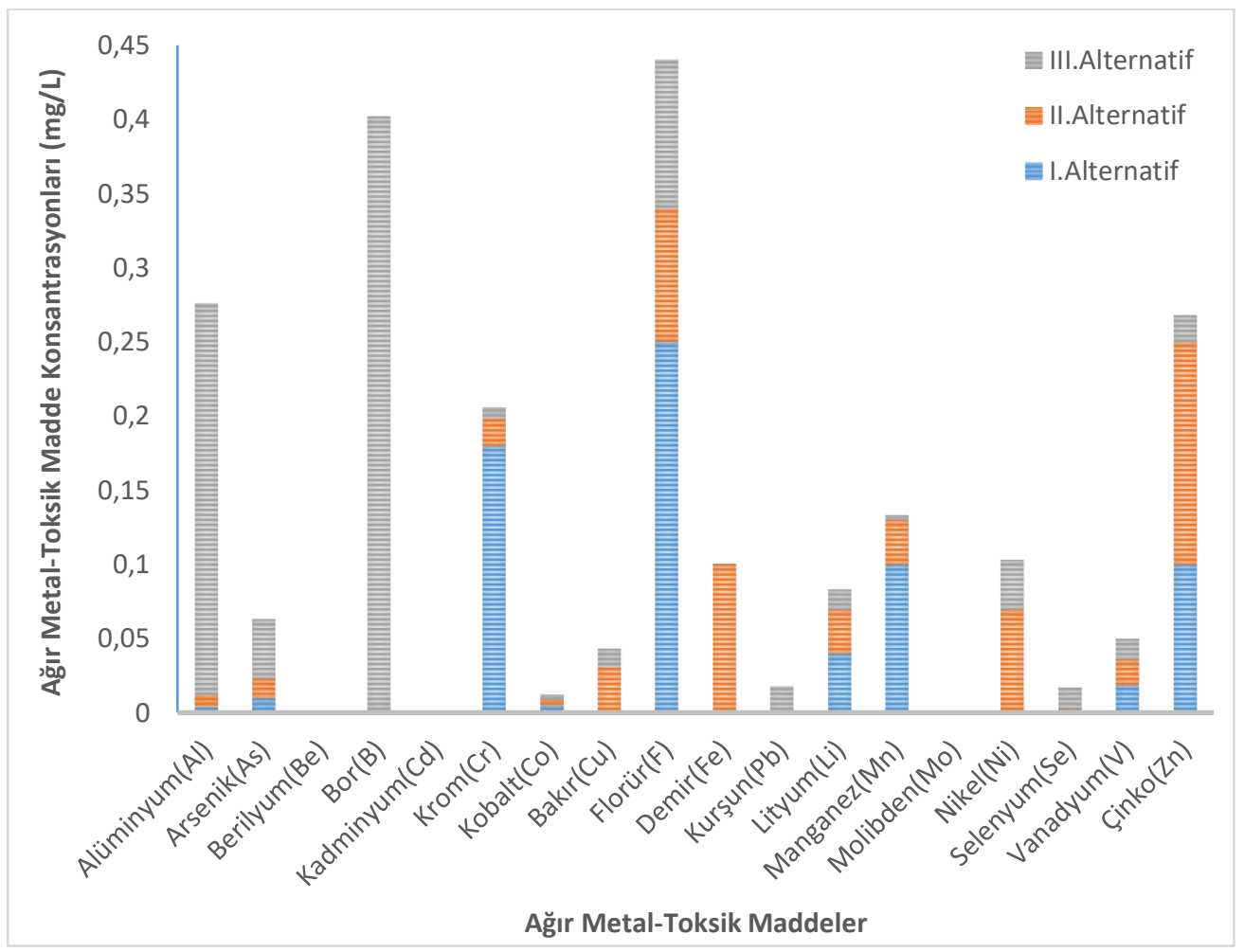

Şekil 5. Pilot tesislerin ağır metal konsantrasyonları

\section{SONUÇ}

Hendek atıksu arıtma tesisinden alınan çıkış suları üç alternatiften oluşan pilot tesislerde ağır metaltoksik element içerikleri açısından değerlendirilmiştir. Bu suların ağır metal içeriklerinin tebliğde verilen yasal sınırların altında kalarak tarımsal alanların sulanmasında güvenle kullanılabileceği görülmüştür. I. alternatif pilot tesisten elde edilen çıkış suyu, diğer tesislerin çıkıș suları ile kıyaslandığında Al, As, $\mathrm{Cu}, \mathrm{Ni}, \mathrm{Zn}$ açısından en düşük konsantrasyon değerlerine sahip olduğu görülmüştür. II. alternatif pilot tesis çıkış suyunda F, Li, Se değerleri ve III. alternatif pilot tesiste ise $\mathrm{Cr}$, $\mathrm{Co}, \mathrm{Fe}, \mathrm{Mn}$, V değerlerinin en düşük konsantrasyonları ölçülmüştür. Cd değerleri ise üç pilot tesis çıkış suyunda da sıfır olarak ölçülmüştür. Bundan sonra yapılacak çalışmalarda tarım potansiyeli yüksek olan bölgemizin ekim yapılan alanlarının sulanmasında arıtılmış atık sular kullanılarak uzun vadede bu suların tarım topraklarının ağır metal içeriklerine olan etkileri belirlenmelidir.

\section{KAYNAKLAR}

1. Tanık, A. ve ark. (2016). Arıtılmış Atıksuların Yeniden Kullanımı ve Yağmur Suyu Hasadı Sistemleri, 2. Baskı, Türkiye Belediyeler Birliği, Ankara, 1-125.

2. Angelakis, A. ve ark. (2014). Water reuse: Overview of current practices and trends in the world with emphasis on EU states, Water Utility Journal, 8, 67- 78.

3. Bixio, D. ve ark. (2006). Wastewater reuse in Europe, Desalination, 187, 89-101.

4. T.C Çevre ve Şehircilik Bakanlığı, Atıksu Eylem Planı 2015-2023.

5. Ak, M ve Top,İ. (2018). Arıtılmış kentsel atıksuların tarımsal sulama amaçlı kullanımı. Pamukkale Univ Muh Bilim Derg, 24(6), 1161-1168.

6. Atıksu Arıtma Tesisleri Teknik Usuller Tebliği, Resmi Gazete Sayısı: 27527, 2010. 
7. Christou, A. ve ark. (2014). Assessment of long-term wastewater irrigation impacts on the soil geochemical properties and the bioaccumulation of heavy metals to the agricultural products, Enviromental Monitoring and Assessment, 186(8), 4857-4870.

8. Kellis, M. ve ark. (2013). Review of wastewater reuse in the Mediterranean countries, focusing on regulations and policies for municipal and industrial applications, Global Nest Journal, 15(3), 333-350.

9. Kurtkulak, H. (2014). Kentsel atıksuların geri kazanımı ve yeşil alanların sulanmasında yeniden kullanımı: Konya kenti örneği, Selçuk Üniversitesi Fen Bilimleri Enstitüsü, Yüksek Lisans Tezi.

10. Duman, H. (2017). Arıtılmış kentsel atık suların sulamada yeniden kullanımı; Kayseri atıksu arıtma tesisi örneği, T.C Orman ve Su İşleri Bakanlı̆̆ı, Uzmanlık Tezi.

11. Solak, Z. (2018). Kentsel nitelikli arıtılmış atık suların tekrar kullanımı (Hendek örneği). Sakarya Üniversitesi Fen Bilimleri Enstitüsü, Yüksek Lisans Tezi. 